\title{
Bolsa Família e Voto na Eleição Presidencial de 2006: em busca do elo perdido?
}

\begin{tabular}{c}
\hline \hline Elaine Cristina Licio \\
Doutoranda do Programa de Pós-Graduação \\
em Política Social da Universidade de Brasilia \\
Lucio R. Rennó \\
Centro de Pesquisa e Pós-Graduação \\
sobre as Américas \\
Universidade de Brasília \\
Henrique Carlos de O. de Castro \\
Centro de Pesquisa e Pós-Graduação \\
sobre as Américas \\
Universidade de Brasília \\
\hline \hline
\end{tabular}

Resumo: 0 presente artigo analisa o impacto de ser beneficiário do Programa Bolsa Família do governo federal na decisão de voto na eleição de 2006 e na avaliação atual do Presidente Lula da Silva e contribui para a crescente literatura que explora o impacto desse programa na distribuição de voto em Lula. Contudo, diferentemente de outros estudos, são analisados aqui dados ao nível individual, testando um modelo estatístico multivariado em uma amostra probabilística nacional usando o Barômetro das Américas de 2008. Os resultados indicam um forte impacto de ser beneficiário do programa no voto em Lula e em avaliações positivas de seu desempenho.

Palavras-chave: Bolsa Família; voto; avaliação governamental

Abstract: This article explores the impact of being a Family Grant Program beneficiary in vote choice for President in the 2006 elections and in Lula da Silva's government evaluations. Therefore, the article contributes to the growing literature on how social programs affect voting behaviour in Brazil. However, differently from all other studies, we use individual level data from the AmericasBarometer 2008 Brazilian round, and multivariate statistical analysis to test our hypotheses. Results indicate that being a recipient of the Family Grant Program positively affects vote for Lula and his administration's evaluations.

Keywords: Bolsa Família; vote; government evaluation

\footnotetext{
1 Agradecemos aos dois pareceristas anônimos da Revista Opinião Pública por seus comentários e sugestões. Os erros remanescentes são de nossa responsabilidade.
} 
Diversas análises têm ressaltado a importância central do Programa Bolsa Família para a reeleição do Presidente Lula no pleito de 2006 (HUNTER e POWER, 2007; NICOLAU e PEIXOTO, 2007, SOARES e TERRON, 2008). Tais estudos creditam em grande parte ao Programa a explicação sobre a mudança do perfil do eleitorado de Lula em relação ao pleito de 2002. Por outro lado, Carraro et al (2007) questionam as análises que atribuem ao Programa Bolsa Família a responsabilidade integral pela reeleição de Lula. Afirmam que não encontraram evidências robustas de que o Programa Bolsa Família - por si só - teve efeito na sua votação.

Em que pese alguma divergência nos achados, tais estudos basearam-se principalmente em dados eleitorais, sociais e econômicos agregados por estados ou municípios para identificar espacialmente os lugares onde houve maior votação em Lula. Dessa forma, sua unidade de análise foi o estado ou município e não o indivíduo. Carraro et al (2007) reconhecem e expressam a limitação desta unidade agregada de análise para verificar correlações que expliquem a reeleição do Presidente da República². Afirmam que, "em dados agregados, as relações que são válidas pelos grupos podem não sê-las para os indivíduos" (CARRARO et al, 2007). Dessa forma, faz-se interessante também investigar, sob o ponto de vista do indivíduo, se existe alguma correlação entre uma avaliação positiva do governo Lula e a participação no Bolsa Família.

Isto é possível a partir da base de dados da Pesquisa "Barômetro das Américas", coordenada pelo Latin American Public Opinion Project (LAPOP). Tal pesquisa é aplicada em vários países do continente americano e retrata atitudes e opiniões de cidadãos em relação a diversos aspectos da cultura política, abordando, inclusive, na etapa brasileira, a avaliação do Governo Federal e o comportamento eleitoral dos entrevistados. Nas rodadas de 2007 e 2008, a etapa brasileira desta Pesquisa incluiu a informação sobre a participação em programas federais de transferência de renda no perfil do entrevistado, o que permite, portanto, identificar possíveis padrões de opiniões e atitudes de beneficiários do Programa Bolsa Família ${ }^{3}$.

Este trabalho se propõe a investigar a relação, no nível individual, entre a participação no Programa Bolsa Família e o voto nas eleições de 2006, assim como

\footnotetext{
2 Soares e Terron (2008) lembram que a inferência de comportamento individual através de agregações é um problema estatístico conhecido como falácia ecológica. Para outras discussões sobre falácia ecológica, veja Robinson (1950), King (1997) e Seligson (2002).

${ }^{3}$ A amostra utilizada aqui, da rodada de 2008, é probabilística nacional, urbana e rural, com 1.500 entrevistas domiciliares realizadas em 120 municípios nos 27 estados e Distrito Federal em abril e maio. A pesquisa foi realizada pelo DATAUnB (Centro de Pesquisa de Opinião Pública da Universidade de Brasília), sob coordenação de Lúcio Rennó e Henrique Carlos de Castro.
} 
a avaliação do desempenho do governo Lula usando a etapa brasileira da Pesquisa "Barômetro das Américas" realizada em 20084. Com isso, poderemos confirmar se os estudos anteriores, baseados em dados agregados, chegaram a conclusões espúrias devido a alguma falácia de agregação ou se seus resultados podem também ser confirmados no nível individual.

$\mathrm{Na}$ primeira parte do artigo discutimos as principais evidências que atribuem a reeleição de Lula à implementação do Programa Bolsa Família. Em seguida fazemos uma breve descrição dos aspectos metodológicos, explicitando as variáveis que integram a pesquisa "Barômetro das Américas" e que são analisadas estatisticamente. Após a análise dos dados segundo as perspectivas teóricas adotadas, passamos às conclusões finais do estudo, que procura responder às seguintes questões: a participação no Bolsa Família se correlaciona com o voto em Lula e com avaliações positivas de seu governo? Em que medida a participação no Programa Bolsa Família está relacionada a uma percepção positiva do cidadão em relação ao Presidente da República e ao governo federal brasileiro?

\section{Principais evidências que atribuem a reeleição de Lula à implementação do Programa Bolsa Família}

A eleição do Presidente Lula em 2002, baseada em um programa de governo com forte apelo social, consolidou a opção pelos programas de transferência de renda no Governo Federal. Todavia, a avaliação do novo governo foi de que, embora tivessem representado um avanço nas políticas sociais brasileiras, estes programas praticamente ignoraram a existência de similares conduzidos por estados e municípios, não conseguindo superar problemas tradicionais como: pulverização de recursos, elevado custo administrativo, superposições de públicos. alvo, competição entre instituições, ausência de coordenação e de perspectiva intersetorial (COHN e FONSECA, 2004).

Assim, formulou-se em 2003 um novo Programa, chamado Bolsa Família, com a finalidade de unificar os procedimentos de execução de ações de transferência de renda do governo federal ${ }^{5}$. O Programa tornou-se o carro-chefe das políticas sociais do governo federal, presente nos 26 estados, no Distrito Federal e em 5.563 municípios, beneficiando cerca de 11 milhões de famílias ou mais de 44 milhões de pessoas (em média, um em cada quatro brasileiros). Em 2008, seu orçamento foi da ordem de $\mathrm{R} \$ 11$ bilhões.

\footnotetext{
${ }^{4}$ Para um estudo semelhante usando dados individuais, mas avaliando o impacto do programa PANES uruguaio nas avaliações dos eleitores sobre seus representantes, veja Manacorda e Vigorito (2009).

${ }^{5}$ Especialmente as do Programa Bolsa Escola, do Programa Cartão Alimentação, do Programa Bolsa Alimentação, do Programa Auxílio-Gás e do Cadastramento Único do Governo Federal.
} 
A inclusão no Cadastro Único é uma pré-condição para a participação das famílias. Aquelas com renda per capita até $\mathrm{R} \$ 60,00$ poderão acumular o benefício básico ( $R \$ 62,00)$ e o variável ( $R \$ 20,00$ por criança, até o limite de três) caso sejam integradas por crianças até 15 anos. Além disso, famílias que tenham adolescentes entre 16 e 17 anos frequentando a escola recebem o benefício variável vinculado ao adolescente ( $\mathrm{R} \$ 30,00$ por adolescente, até o limite de dois). O valor do benefício pago à família é definido de acordo com sua composição e renda per capita, variando de $\mathrm{R} \$ 20,00$ a $\mathrm{R} \$ 182,00$. O recebimento do benefício está condicionado ao acesso aos direitos sociais básicos: manter as crianças na escola, acompanhar as gestantes, monitorar a nutrição e a vacinação das crianças. As principais razões para desligamento do Programa são: aumento no valor da renda per capita da família para valor acima dos critérios de elegibilidade do Programa e descumprimento reiterado das suas condicionalidades, nos termos da Portaria GM/MDS n 551, de 09 de novembro de 2005 (MDS, 2008).

No que se refere à forma de funcionamento do Programa Bolsa Família, resumidamente, o governo federal coordena, financia a gestão e paga os benefícios diretamente às famílias; os governos estaduais apoiam tecnicamente os municípios e estes, por sua vez, executam diretamente o Programa, por meio do cadastro dos beneficiários, controle das condicionalidades, gestão de benefícios e acompanhamento das famílias. A exemplo do que já ocorre com a maioria das ações federais descentralizadas, o Programa conta com uma instância de controle social local, composta por representantes do governo e da sociedade. Municípios e estados também podem complementar os benefícios pagos pelo Programa, integrando-os ou não a eventuais programas próprios de transferência de renda. Além disso, devem promover a articulação das ações para assegurar o seu caráter intersetorial, sobretudo com relação às políticas regionais e locais de saúde, educação, assistência social e trabalho.

Como se vê, o Programa é descentralizado e fortemente focalizado. Além disso, é visto como um importante fator de redução da pobreza e da desigualdade (IPEA, 2006). Para participar, além de satisfazer os critérios de elegibilidade, basta ser cadastrado pelo município, sem intermediações políticas. Segundo Hunter e Power (2007), é importante destacar este aspecto, pois difere do clientelismo tradicional, onde o recebimento de benefícios sociais está vinculado à lealdade política. No caso do Programa Bolsa Família, não há nenhuma penalidade para o beneficiário que eventualmente vote contrário ao governo, uma vez que, aparentemente, não há qualquer critério político para o cadastramento do cidadão no Cadastro Único para o recebimento do benefício ${ }^{6}$.

${ }^{6}$ Castro (2008) argumenta que o Bolsa Família é uma renovação da política coronelista tradicional por romper com os paradigmas das políticas compensatórias, que não levam a um ciclo de mudança da 
A expansão do Programa foi rápida, mesmo nos estados e municípios comandados pela oposição. Ao final de 2004 , alcançava $59 \%$ da sua meta, ao final de 2005 chegou a $80 \%$, finalmente alcançando $100 \%$ da sua meta de 11,1 milhões de famílias em junho de 2006 (TCU, 2007).

Segundo análise de Nicolau e Peixoto (2007), o Programa foi eficiente em alocar recursos nas cidades mais pobres do país. A correlação entre o gasto do Bolsa Família e os quatro indicadores sociais selecionados (taxa de analfabetismo de adultos, percentual de pobres, renda per capita e esperança de vida ao nascer) é alta. Ou seja, quanto pior a situação do município, maiores tendem a ser os recursos recebidos. Junto com o aumento do salário mínimo e demais melhorias na economia, o Programa repercutiu positivamente para a mobilidade social - a pobreza absoluta reduziu de $28 \%$ para $23 \%$ nos primeiros três anos do governo Lula (NERI, 2006). O Banco Mundial, o Banco Interamericano de Desenvolvimento e até mesmo o Fundo Monetário Internacional têm enfatizado as qualidades do Programa ${ }^{7}$.

O sucesso do Programa Bolsa Família na redução da pobreza e da desigualdade é portanto reconhecido nacional e internacionalmente. Mas teria alguma relação com a reeleição de Lula?

Nicolau e Peixoto analisaram os determinantes do voto em Lula em 2006 através de testes econométricos e mostraram-se convictos do efeito Bolsa Família. Em 2006, Lula recebeu $61 \%$ dos votos válidos no segundo turno, o mesmo percentual que havia recebido quatro anos antes. Todavia, percebeu-se que o perfil do eleitorado de Lula havia se alterado. Os autores identificaram a correlação entre alguns indicadores sociais e a sua votação, demonstrando que, em 2002, quanto melhor a situação social do município, maior foi a sua votação. Entretanto, quando a mesma análise foi feita para 2006, o cenário inverteu-se: à medida que os indicadores pioram, maior é a votação de Lula. Para os autores, a implementação do Programa Bolsa Família foi fundamental para explicar a variação dos votos entre os dois pleitos presidenciais.

Os autores (2007) colocaram ainda esta relação em termos lógicos: 1. em 2002, Lula teve votação bem distribuída pelo país, mas proporcionalmente melhor nas áreas mais desenvolvidas; 2. ao longo do mandato, o governo implementou uma série de programas dirigidos às cidades com menor desenvolvimento social e entre esses programas, destaca-se o Bolsa Família, que investiu mais de 17 bilhões em quatro anos nas áreas onde se concentra a população pobre; 3. em 2006, as áreas que mais se beneficiaram das políticas implementadas pelo governo federal

situação de vida dos beneficiários. No entanto, o argumento não se baseia em sanção aos beneficiários por suas posições políticas, mas na manutenção da situação de dependência.

7 Para mais leituras sobre o Programa Bolsa Família não diretamente relacionadas ao seu impacto eleitoral e, portanto, de importância secundária para este artigo, veja: Hoffman, 2006; IPEA, 2006; Paes de Barros et al, 2006 e Soares et al, 2006. 
(particularmente municípios de baixa renda, majoritariamente concentrados nas regiões norte e nordeste) votaram no candidato que implementou essas políticas.

Hunter e Power (2007) também consideraram a hipótese do Programa Bolsa Família como o fator mais relevante para a vitória de Lula no último pleito. Em estudo que aborda o efeito das denúncias de corrupção no governo Lula nas eleições de 2006, os autores afirmaram que o desempenho do Presidente foi melhor entres eleitores que pertencem a famílias cuja renda per capita é inferior a dois salários mínimos, um segmento que compreende cerca de $47 \%$ do eleitorado brasileiro. Os autores adirmaram ainda que, segundo teóricos da modernização e da mudança cultural, indivíduos com menor segurança econômica colocam necessidades básicas acima de assuntos como ética e transparência na política (INGLEHART and WELZEL, 2005, APUD HUNTER e POWER, 2007). Ou seja, ainda que as denúncias de corrupção tenham sido graves, elas não afetaram o voto em Lula nos estados e municípios mais pobres, com menor Índice de Desenvolvimento Humano - IDH.

Por outro lado, embora também reconheçam que o Bolsa Família teve um impacto positivo na votação do presidente eleito, Carraro et al (2007) questionam a contundência com que os demais autores afirmam esta relação, referindo-se aos trabalhos de Hunter e Power (2007) e Nicolau e Peixoto (2007):

\begin{abstract}
"As afirmações são algo audaciosas para um trabalho preliminar baseado em especificação econométrica questionável [referindo-se ao trabalho de Nicolau e Peixoto (2007)]. A variável Bolsa Família per capita está correlacionada com o percentual de pobres na população. Esta, por sua vez, é correlacionada com a votação de Lula, fazendo com que seja mais do que esperado que a votação de Lula esteja correlacionada com a parcela de beneficiados pelo Bolsa Família na população. Correlação não implica em causalidade [sic] e há uma possível variável que intermedeia (o percentual de pobres no município) a relação entre a proxy da Bolsa Família e a votação de Lula" (CARRARO et al, 2007).
\end{abstract}

A partir de estudos econométricos que agregam outras variáveis ${ }^{8}$ aos estudos citados, Carrato et al (2007) afirmam que, embora a votação de Lula realmente tenha sido maior nos estados e municípios mais pobres, desiguais e com mais analfabetos não encontraram evidências robustas de que o Programa Bolsa Família - por si só - teve efeito na votação de Lula.

Soares e Terron (2008) adentram esse debate tentando responder a algumas críticas feitas por Carrato et al (2007). Segundo os padrões geográficos da

${ }^{8}$ Como desigualdade, distância do município à capital do estado, densidade demográfica e mortalidade infantil. 
votação municipal e o que denominam de coesão regional das bases geoeleitorais mudaram entre 2002 e 2006. Aqueles autores se perguntam, então, o que gerou a mudança entre os dois episódios eleitorais e seguem a hipótese, defendida por Nicolau e Peixoto (2007) e Hunter e Power (2007) de que o Bolsa Família foi fundamental no crescimento da votação de Lula nos municípios mais pobres do norte e nordeste do país. Em sua análise, Soares e Terron atenuam problemas analíticos encontrados nos textos anteriores e apontados por Carrato et al (2007) e concluem que a participação do Programa Bolsa Família sobre a renda local foi um determinante deste novo contorno das bases geoeleitorais, e o fator com maior peso na explicação da votação municipal.

Esse debate deixa claro que o Programa Bolsa Família teve implicações significativas para o resultado da eleição de 2006, favorecendo fortemente Lula da Silva. Contudo, o fato de todas as inferências terem sido extraídas de dados agregados por municípios ou estados não implica que os beneficiários do Bolsa Família reelegeram Lula em 2006, pois o comportamento dos eleitores individualmente não foi apurado. Eis o elo perdido dessa linha de pesquisa. Para investigar melhor esta relação faz-se necessário trabalhar no nível das opiniões e atitudes individuais. Se a hipótese destes autores estiver correta, este tipo de análise encontrará pelo menos alguma magnitude e significância estatística entre o fato de participar do Programa Bolsa Família e avaliar positivamente o Presidente da República e o governo federal. Este é o objetivo deste trabalho, cujos aspectos metodológicos expomos a seguir.

\section{Aspectos metodológicos}

O presente estudo baseia-se em dados da etapa brasileira da Pesquisa "Barômetro das Américas", coordenada pelo Latin American Public Opinion Project (LAPOP) e realizada entre abril e maio de 2008. A população objeto da pesquisa consiste de cidadãos brasileiros, com 18 anos ou mais, residindo no país. A pesquisa é realizada por meio de uma amostra probabilística nacional, com um total de 1.497 pessoas entrevistadas ${ }^{9}$.

Para desenvolver este trabalho, utilizamos como principal variável dependente ser beneficiário do Programa Bolsa Família. O entrevistado que respondeu "Sim" a pelo menos uma das alternativas seguintes foi considerado beneficiário e recebeu valor 1 em uma variável dicotômica que diferencia beneficiários de não-beneficiários ${ }^{10}$.

${ }^{9} \mathrm{O}$ país foi estratificado em cinco regiões: norte, nordeste, centro-oeste, sudeste e sul. A amostra completa foi composta de $53,7 \%$ de homens e $46,3 \%$ de mulheres. Outras informações sobre a Pesquisa poderão ser encontradas na página <www.AmericasBarometer.org $>$.

10 Cabe lembrar que o Programa Bolsa Família unificou os programas de transferência de renda do governo federal. Cremos que a manutenção desta diferenciação entre os programas no questionário se 
OPINIÃO PÚBLICA, Campinas, vol. 15, nº 1, Junho, 2009, p.31-54

\begin{tabular}{|c|l|l|l|l|}
\hline \multicolumn{2}{|c}{ O(a) sr(a) participa do Programa } & \multicolumn{3}{c|}{, do Governo Federal ? } \\
\hline código & \multicolumn{1}{|c|}{ Variável } & SIM (1) & NÃO (2) & NS/NR (8) \\
\hline BF1A & Bolsa Família & & & \\
\hline BF1B & Bolsa Escola & & & \\
\hline BF1C & Bolsa Alimentação & & & \\
\hline BF1D & Vale Gás & & & \\
\hline
\end{tabular}

Fonte: Questionário; “A Cultura Política da Democracia”. Brasil, 2008. DATAUnB. Pesquisa Americas Barometer. Latin American Public Opinion Project (LAPOP).

Como variáveis dependentes enfocamos o voto em Lula em 2006 e a avaliação do trabalho do presidente, de forma a ampliar a robustez de nossos achados ao avaliar como a participação no Programa Bolsa Família influencia distintas relações entre eleitor e o governo Lula.

\begin{tabular}{|c|l|l|c|}
\hline Código & \multicolumn{1}{|c|}{ Variável } & \multicolumn{1}{|c|}{ Respostas possíveis } & Tipo \\
\hline vb3 & $\begin{array}{c}\text { Em qual dos candidatos o sr./sra. } \\
\text { votou para Presidente no 1o turno } \\
\text { das eleições presidenciais em } \\
2006 ?\end{array}$ & $\begin{array}{l}\text { Lista de candidatos; (77) Outro; } \\
\text { (88) NS/NR; (99) NSA/não } \\
\text { votou }\end{array}$ & \multirow{2}{*}{ nominal } \\
\hline Bravb4 & $\begin{array}{l}\text { Em qual dos candidatos o sr./sra. } \\
\text { votou para Presidente no 2o turno } \\
\text { das eleições presidenciais em } \\
\text { m1 }\end{array}$ & $\begin{array}{l}\text { Lista de candidatos; (77) Outro; } \\
\text { (88) NS/NR; (99) NSA/não } \\
\text { votou }\end{array}$ & \\
& $\begin{array}{l}\text { Como o sr./sra. avalia o trabalho } \\
\text { quealizando? }\end{array}$ & $\begin{array}{l}\text { (1) Muito bom (2) Bom (3) Nem } \\
\text { bom, nem mal (regular) (4) Mal } \\
\text { (5) Muito mal (péssimo) (8) } \\
\text { NS/NR }\end{array}$ & \multirow{2}{*}{ ordinal } \\
\hline
\end{tabular}

Fonte: Questionário: "A Cultura Política da Democracia”. Brasil, 2008. DATAUnB. Pesquisa Americas Barometer. Latin American Public Opinion Project (LAPOP).

Além dessas variáveis, o modelo multivariado de explicação do voto e do apoio ao governo Lula inclui outras variáveis consideradas importantes pela literatura especializada em comportamento eleitoral e que estão disponíveis no questionário do Barômetro das Américas. Fazem parte da equação, portanto: identificação partidária com o PT, autoposicionamento à esquerda em uma escala ideológica, percepções sobre a economia e corrupção como principais problemas

deve ao fato de que os beneficiários dos programas remanescentes ainda estavam em processo de troca dos respectivos cartões magnéticos pelos do Bolsa Família no momento da pesquisa, podendo se confundir na hora da resposta e achar que não participavam do Programa Bolsa Família. 
do país, avaliações retrospectivas do estado da economia no país, além de controles socioeconômicos (CARREIRÃO, 2002 e 2007; NICOLAU, 2007; RENNÓ, 2007). Acrescentamos também na análise, e isso é especialmente relevante no estudo dos determinantes da avaliação da administração Lula, satisfação com a vida na localidade onde mora e ter sido vítima de crime, ambos fatores que podem influenciar a avaliação do governo.

Um ponto importante nessa análise, que merece destaque, é a distância temporal da coleta dos dados sobre intenção de voto e a eleição. Possivelmente, quanto mais distante da eleição é a coleta de dados sobre decisões eleitorais, mais imprecisa é a declaração de voto. Também é possível que em surveys pós-eleitorais haja uma inflação de eleitores que dizem ter votado no candidato vencedor. De fato, a Tabela 1 indica algumas diferenças quando comparamos os dados coletados em 2008, na rodada brasileira do Barômetro das Américas (BA) e no Estudo Eleitoral Brasileiro (ESEB), coletado em 2006, logo após as eleições. Também contrastamos os achados dessas pesquisas com o resultado oficial divulgado pelo TSE em seu sítio na internet.

Fica claro que há diferenças nas pesquisas de opinião pública. O voto no candidato vencedor é inflacionado no primeiro turno e reduzido no segundo turno. No entanto, as diferenças são menos marcantes no que tange à votação declarada a Lula do que quanto aos demais candidatos, principalmente o segundo colocado. Já no que tange à comparação das pesquisas eleitorais feitas em momentos distintos, ocorre um aumento no índice de não resposta e uma redução na votação de outros candidatos no Barômetro das Américas, realizada mais tempo após a eleição do que o ESEB. Ou seja, os eleitores que não votaram em Lula preferem esquecer em quem votaram ou se abster de responder à questão, na medida em que passa o tempo. Claramente, isso está associado aos altos índices de popularidade de Lula em 2008. Caso contrário, talvez esses índices fossem mais baixos. De qualquer forma, fica claro que as pesquisas têm distorções que precisam ser levadas em consideração e tratadas na análise. 
Tabela 1.

Frequência de Votos Declarados nos Principais Candidatos no Primeiro e Segundo Turno de 2006 nas pesquisas Barômetro das Americas e ESEB e o resultado oficial da eleição declarado pelo TSE.

\begin{tabular}{|c|c|c|c|c|c|c|}
\hline Candidato & $\begin{array}{c}\text { Primeiro } \\
\text { Turno - } \\
\text { TSE } \\
\end{array}$ & $\begin{array}{c}\text { Primeiro } \\
\text { Turno - } \\
\text { BA }\end{array}$ & $\begin{array}{c}\text { Primeiro } \\
\text { Turno - } \\
\text { ESEB }\end{array}$ & $\begin{array}{c}\text { Segundo } \\
\text { Turno - } \\
\text { TSE }\end{array}$ & $\begin{array}{c}\text { Segundo } \\
\text { Turno - } \\
\text { BA }\end{array}$ & $\begin{array}{c}\text { Segundo } \\
\text { Turno - } \\
\text { ESEB }\end{array}$ \\
\hline Lula da Silva & $49 \%$ & $56 \%$ & $56 \%$ & $61 \%$ & $59 \%$ & $56 \%$ \\
\hline $\begin{array}{l}\text { Geraldo } \\
\text { Alckmin }\end{array}$ & $42 \%$ & $14 \%$ & $20 \%$ & $39 \%$ & $14 \%$ & $22 \%$ \\
\hline Heloisa Helena & $07 \%$ & $02 \%$ & $04 \%$ & & .. & \\
\hline $\begin{array}{c}\text { Cristovam } \\
\text { Buarque }\end{array}$ & $03 \%$ & $0,4 \%$ & $01 \%$ & & .. & \\
\hline $\begin{array}{l}\text { NR/NS em } \\
\text { branco, nulo }\end{array}$ & & $29 \%$ & $18 \%$ & & $27 \%$ & $22 \%$ \\
\hline
\end{tabular}

Fonte: Barômetro das Americas, 2008; ESEB, 2006; TSE, 2006.

Nesse sentido, vale destacar que o padrão de resposta, então, não enviesa tão dramaticamente o voto em Lula quando comparado com todas as demais opções, mas causaria problemas se fôssemos contrastar o voto de Lula com cada uma das possíveis escolhas de candidatos disponíveis. Isso tem implicações para o tipo de estimação que devemos utilizar para avaliar o voto. O ideal é sempre contrastar o voto do principal candidato com cada uma das demais opções, usando um modelo probit ou logit multinominal, para respeitar de forma mais adequada a própria natureza pluritômica da variável dependente. Contudo, como os votos dos demais candidatos no primeiro turno de 2006, usando o Barômetro das Américas, foram atenuados pelo tempo, o uso do logit multinominal é prejudicado. Assim, preferimos diferenciar o voto em Lula de todas as demais opções excluindo os valores ausentes da análise. Portanto, para as análises de voto em 2006, tanto no primeiro quanto no segundo turnos, usamos variáveis dependentes dicotômicas onde voto declarado em Lula recebe valor 1 e voto em outros candidatos valor 0 . Assim, estimamos o modelo usando uma função de ligação probit.

Apesar disso, embora as diferenças não sejam tão grandes no tempo, cabe destacar que os dados sobre ser beneficiário do Programa Bolsa Família dizem respeito a 2008 e não a 2006. Ou seja, estamos inferindo que os beneficiários são os mesmos de 2006, o que pode não ser o caso. Isso gera problemas de antecedência do efeito (voto) sobre a causa (participação no programa), levando a potencial problema de endogeneidade. Embora não seja possível ter certeza de que os entrevistados pelo Barômetro das Américas já faziam parte do Programa Bolsa 
LICIO, E.; RENNÓ, L. R.; CASTRO, H. C. O. Bolsa Família e voto na eleição...

Família quando votaram em 2006, podemos medir a probabilidade de que isso tenha ocorrido. Sabemos que, desde que o Programa atingiu sua meta de 11.102.770 famílias, a inclusão de novas famílias só é permitida quando outras são desligadas. Dessa forma, as concessões mensais são feitas basicamente a partir dos cancelamentos ocorridos no mês. Segundo informações do MDS, 2.500.265 famílias novas entraram no Programa desde julho de 2006, o que nos permite inferir que cerca de $22 \%$ das 11,1 milhões de famílias que estão no Programa hoje não faziam parte do mesmo por ocasião das eleições daquele ano. Esse fato limita a análise do impacto total do Bolsa Família no voto, medido tanto tempo após a eleição, já que exclui da análise pessoas que, no momento da eleição, beneficiavam. se do programa. Se encontrarmos tal relação, isso é sinal de que, em uma amostra mais adequada, o efeito seria ainda maior.

Assim, por conta das diferenças entre o voto declarado e o resultado oficial da eleição divulgado pelo TSE e a questão temporal acerca do voto e ser beneficiário, insistimos na necessidade de analisar também o impacto de ser beneficiário do Bolsa Família na avaliação do trabalho do presidente Lula, que apresenta a seguinte distribuição:

Tabela 2

Avaliação do Desempenho do Presidente Lula: Brasil 2008.

\begin{tabular}{|l|c|}
\hline & Avaliação Lula \\
\hline Muito Bom & $12 \%$ \\
\hline Bom & $38 \%$ \\
\hline Nem Bom Nem Mal & $39 \%$ \\
\hline Mal & $6 \%$ \\
\hline Muito Mal & $4 \%$ \\
\hline Não Respondeu & $1 \%$ \\
\hline
\end{tabular}

Fonte: Pesquisa "Barômetro das Américas", 2008.

Como essa é uma variável ordinal, usamos uma função probit ordinal para estimar o impacto das variáveis independentes. Nesse caso, não há problemas de endogeneidade, já que ser beneficiário do Programa antecede a avaliação realizada em abril e maio de 2008 e não há evidências de que apenas apoiadores de Lula participam do Programa Bolsa Família. Ao contrário, a identificação e inscrição no Cadastro Único das famílias em situação de pobreza e extrema pobreza e a gestão dos benefícios é de competência dos municípios, o que é um indicativo forte de que o governo federal não manipula a indicação de beneficiários, uma vez que a 
distribuição das forças político-partidárias nos municípios não necessariamente segue a lógica federal ${ }^{11}$.

Assim, através da análise de duas variáveis dependentes distintas, pretendemos aumentar a robustez de nossos achados sobre o impacto do Bolsa Família na disputa política-eleitoral brasileira.

\section{Análise dos dados}

Na pesquisa cerca de $18,4 \%$ dos entrevistados são beneficiários do Programa Bolsa Família (276, do total de 1497). Esta proporção não está muito longe do percentual de beneficiários do Programa em relação à população brasileira (cerca de 23\%). Os beneficiários nesta amostra possuem em média 5,4 anos de estudo, enquanto os não beneficiários possuem em média 7,7 anos de estudo. Quarenta e cinco por cento dos beneficiários do Programa possuem renda familiar inferior a um salário mínimo, enquanto cerca da metade dos não beneficiários possuem renda familiar entre um e três salários mínimos. A idade média dos beneficiários do Programa é de quarenta anos, enquanto dos não beneficiários é de quarenta e dois anos. Como vimos, dentre as variáveis analisadas, com exceção dos anos de estudo, o perfil dos beneficiários não se distancia muito do perfil dos não beneficiários entrevistados.

Em primeiro lugar, cabe explorar algumas análises descritivas e bivariadas para melhor entendermos como beneficiários do Programa Bolsa Família se diferenciam dos não beneficiários. Por serem variáveis nominais, usamos primeiro a comparação entre a moda dos beneficiários e não beneficiários no que tange ao voto.

\footnotetext{
${ }^{11}$ Em relatório de acompanhamento do Programa Bolsa Família, onde avalia seu processo de expansão, - TCU afirma não ter encontrado evidências de favorecimento a partido político específico nem descumprimento de norma legal que pudessem caracterizar utilização do Programa com finalidades eleitoreiras no nível federal. Afirmam que a seleção de beneficiários feita pelo governo federal atende a uma ordem de procedimentos pré-definidos, na qual não se constatou viés político. Além disso, a cobertura do Programa Bolsa Família superava, em junho de 2006, a estimativa de famílias pobres nos estados governados pelos principais partidos (PT, PSDB e PFL). A cobertura percentual dos estados governados pelo PMDB foi de cerca de $97 \%$ em virtude da baixa cobertura do Programa no Distrito Federal e no estado do Rio de Janeiro, que ocorreu por problemas que vão desde insuficiência de cadastros válidos para expansão do Programa até questões operacionais decorrentes da integração do Programa Bolsa Família com programas locais de transferência de renda - caso do DF (TCU, 2007).
} 
LICIO, E.; RENNÓ, L. R.; CASTRO, H. C. O. Bolsa Família e voto na eleição...

Tabela 3

Moda relativa às variáveis que indicam comportamento eleitoral do beneficiário do Programa Bolsa Família

\begin{tabular}{|c|l|c|c|c|}
\hline \multicolumn{3}{|c|}{ Variável Dependente } & PBF & não PBF \\
\hline cod & \multicolumn{1}{|c|}{ Nome } & resposta & $\left(^{*}\right)$ & $\left(^{*}\right)$ \\
\hline Vb20 & em quem votaria para Presidente hoje? & $\begin{array}{c}\text { Lula ou } \\
\text { PT }\end{array}$ & $62,30 \%$ & $40,69 \%$ \\
\hline Vb3 & $\begin{array}{l}\text { em quem votou para Presidente 10 } \\
\text { turno? }\end{array}$ & Lula & $85,84 \%$ & $70,35 \%$ \\
\hline bravb4 & $\begin{array}{l}\text { em quem votou para Presidente 20 } \\
\text { turno? }\end{array}$ & Lula & $86,38 \%$ & $72,38 \%$ \\
\hline
\end{tabular}

Fonte: Pesquisa "Barômetro das Américas", 2008.

$\left({ }^{*}\right)$ porcentagem de respondentes, excluídos missings.

A Tabela 3 mostra que em todas as variáveis a moda confere com a categoria relacionada ao Presidente Lula, tanto para beneficiários quanto para não beneficiários do Programa Bolsa Família. Ou seja, a maior parte dos dois grupos de entrevistados votou em Lula nas últimas eleições (nos dois turnos) e ainda votaria caso as eleições ocorressem hoje. No entanto, há evidências de que o comportamento eleitoral está relacionado com o fato de pertencer ao Programa Bolsa Família. No que se refere à atitude dos beneficiários do Programa, a porcentagem de voto em Lula foi cerca de $15 \%$ maior no primeiro e segundo turnos de 2006, e 22\% maior caso a eleição ocorresse no momento de realização da entrevista. Sob o ponto de vista do comportamento eleitoral, portanto, isso mostra que os beneficiários do Programa Bolsa Família possuem maior tendência a votar em Lula do que os não-beneficiários.

Há, também, uma associação estatisticamente significativa entre ser beneficiário do Bolsa Família e a opinião ou atitude positiva em relação ao Presidente da República e ao governo federal, mas isso varia de acordo com as diversas esferas de suas atuações ${ }^{12}$.

12 Ressaltamos que os casos ausentes ou 'missing' não foram expressivos em nenhuma das variáveis selecionadas e foram excluídos da análise. A operacionalização das variáveis está descrita nos anexos. 
Tabela 4

Coeficiente de correlação da percepção positiva do Presidente da República e do governo federal por parte dos beneficiários do Bolsa Família

\begin{tabular}{|c|l|c|}
\hline \multicolumn{2}{|c|}{ Variável Dependente } & Gamma \\
\hline código & \multicolumn{1}{|c|}{ Assunto } & $0,19^{* * *}$ \\
\hline n13braz & $\begin{array}{l}\text { Governo federal investe em proteger meio } \\
\text { ambiente? }\end{array}$ & $0,22^{* * *}$ \\
\hline n3 & $\begin{array}{l}\text { Governo federal promove e protege princípios } \\
\text { democráticos? }\end{array}$ & $0,24^{* * *}$ \\
\hline n10 & Governo federal protege direitos humanos? & $0,25^{* * *}$ \\
\hline n12 & Governo federal combate o desemprego? & $0,26^{* * *}$ \\
\hline n9 & Governo federal combate a corrupção do governo? & $0,29^{* * *}$ \\
\hline n11 & Governo federal melhora segurança do cidadão? & $0,32^{* * *}$ \\
\hline B21a & Confiança no Presidente da República? & $-0,33^{* * *}$ \\
\hline m1 & $\begin{array}{l}\text { Avalia negativamente o trabalho do Presidente } \\
\text { Lula? }\end{array}$ & $0,35^{* * *}$ \\
\hline b14 & Confiança no governo federal? & $0,41^{* * *}$ \\
\hline n1 & Governo federal combate a pobreza? & \\
\hline
\end{tabular}

Níveis de significância: *** $p<0,01 * * p<0,05 * p<0,10$

Fonte: Pesquisa "Barômetro das Américas", 2008.

Para fins de análise da magnitude estatística da associação entre estas variáveis podemos dividi-las em dois grupos. As primeiras seis variáveis se referem à opinião do entrevistado sobre o desempenho do governo federal em relação a diversas políticas públicas, não diretamente relacionadas ao Programa Bolsa Família. Nestas variáveis o coeficiente de correlação é mais baixo (entre 0,19 e 0,29 ) do que no segundo grupo de variáveis, mais diretamente relacionadas a temas próximos ao Programa Bolsa Família. Isso demonstra que, embora exista, é fraca a associação entre pertencer ao Programa Bolsa Família e avaliar positivamente o governo federal em todos os seus aspectos. Os eleitores, portanto, parecem saber diferenciar as distintas áreas de atuação do governo federal e avaliálas correspondentemente.

Todavia, observamos uma crescente correlação no outro conjunto de variáveis, que envolvem diretamente a avaliação do trabalho do Presidente e do governo em temas mais afetos ao perfil dos beneficiários do Programa Bolsa Família, inclusive uma avaliação geral do governo. Observa-se que, para este conjunto, o coeficiente gamma varia de 0,32 a 0,41, destacando-se a maior destas correlações na avaliação sobre o desempenho do governo federal no combate à pobreza. 0 sinal positivo das 
variáveis analisadas indica uma relação direta entre o fato de participar do Programa Bolsa Família e avaliar positivamente o governo e o Presidente.

Todos os testes Chi2 ( $p$ ) confirmam a significância estatística dos resultados, permitindo generalizações para a população nacional com menos de $1 \%$ de chance de erro.

Mas essas análises são insuficientes para chegarmos a uma conclusão definitiva sobre o impacto de ser beneficiário do Programa Bolsa Família em escolhas políticas concretas dos cidadãos. Para isso, precisamos modelar voto e avaliações do governo controlando por outras explicações possíveis, a fim de reduzir a possibilidade de espuriedade nos achados bivariados. Dessa forma, apresentamos em seguida análises multivariadas dos determinantes do voto em Lula em 2006 e da avaliação de seu desempenho em 2008. Esse é, portanto, o grande diferencial deste artigo: testamos o impacto de ser beneficiário do Bolsa Família no voto em Lula e na avaliação de seu governo controlando por outras possíveis explicações.

Fica claro na Tabela 5 que ser beneficiário do Programa Bolsa Família tem um impacto estatisticamente significativo e substantivamente grande na probabilidade de voto em Lula tanto no primeiro quanto nos segundo turnos. Visões sobre a corrupção, avaliações retrospectivas sociotrópicas (estado da economia nacional) e identificação com o Partido dos Trabalhadores também foram fatores decisivos na escolha por Lula em 2006. Esses achados confirmam os resultados encontrados por Rennó embasados no ESEB 2006, quando um modelo quase idêntico foi testado $(2007)^{13}$.

13 Rennó (2007) não testou o impacto da participação no Programa Bolsa Família porque o ESEB 2006 não dispunha dessa variável. 


\section{Tabela 5}

Efeitos marginais estimados através de um modelo probit para Voto em Lula no Primeiro e Segundo Turno de 2006: Brasil 2008.

\begin{tabular}{|l|c|c|}
\hline & Primeiro Turno & Segundo Turno \\
\hline Beneficiário do Programa Bolsa Família & 0.10 & 0.08 \\
\hline & $(0.03)^{* * *}$ & $(0.03)^{* * * *}$ \\
\hline Corrupção como Principal Problema do País & -0.10 & -0.08 \\
\hline Economia como Principal Problema do País & $(0.05)^{* *}$ & $(0.04)^{*}$ \\
\hline & -0.01 & -0.00 \\
\hline Avaliação Retrospectiva Sociotrópica & $(0.03)$ & $(0.03)$ \\
\hline & 0.03 & 0.03 \\
\hline Atenção à Mídia & $(0.01)^{* *}$ & $(0.01)^{* *}$ \\
\hline & -0.00 & -0.00 \\
\hline Identificação com o Partido dos Trabalhadores & $(0.01)$ & $(0.01)$ \\
\hline & 0.21 & 0.19 \\
\hline Auto-Posicionamento Ideológico à Esquerda & $(0.02)^{* * *}$ & $(0.02)^{* * *}$ \\
\hline & 0.02 & 0.04 \\
\hline Homem & $(0.04)$ & $(0.03)$ \\
\hline & 0.03 & 0.02 \\
\hline Escolaridade & $(0.03)$ & $(0.02)$ \\
\hline & -0.01 & -0.01 \\
\hline N & $(0.00)^{* * *}$ & $(0.00)^{* * * *}$ \\
\hline
\end{tabular}

Fonte: Pesquisa "Barômetro das Américas", 2008

Erros-Padrão Robustos em Parênteses

* significativo a $10 \%$; ${ }^{* *}$ significativo a $5 \%$; ${ }^{* * *}$ significativo a $1 \%$

Já no que tange a avaliação do desempenho em 2008 do Presidente Lula da Silva, ser também beneficiário do Programa Bolsa Família segue as expectativas desse estudo, conforme se pode ver na Tabela 6. Ser beneficiário do Programa aumenta em muito a probabilidade de avaliar Lula positivamente. Cabe destacar que visões sobre corrupção, avaliação retrospectiva sociotrópica e identificação com - Partido dos Trabalhadores são também decisivos nas avaliações dos cidadãos brasileiros sobre o desempenho do governo, indicando uma forte associação entre determinantes do voto e da avaliação de governos no Brasil. 
LICIO, E.; RENNÓ, L. R.; CASTRO, H. C. O. Bolsa Família e voto na eleição...

Tabela 6

Coeficientes Probit Ordenados para Avaliação do Governo Lula: Brasil, 2008.

\begin{tabular}{|l|c|}
\hline & $\begin{array}{c}\text { Avaliação do } \\
\text { Governo } \\
\text { Lula }\end{array}$ \\
\hline Beneficiário do Programa Bolsa Família & 0.45 \\
\hline Corrupção é o Problema mais Grave do País & $(0.08)^{* * *}$ \\
\hline & -0.22 \\
\hline Economia é o Problema mais Grave do País & $(0.09)^{* * *}$ \\
\hline & 0.00 \\
\hline Avaliação Retrospectiva Sociotrópica & $(0.09)$ \\
\hline & 0.29 \\
\hline Satisfação com a Vida em sua Cidade & $(0.04)^{* * *}$ \\
\hline & 0.10 \\
\hline Vítima de Crime no Último Ano & $(0.07)$ \\
\hline & 0.09 \\
\hline Atenção à Mídia & $(0.07)$ \\
\hline & -0.02 \\
\hline Identificação com o Partido dos Trabalhadores & $(0.01)$ \\
\hline & 0.76 \\
\hline Auto-Posicionamento Ideológico à Esquerda & $(0.09)^{* * *}$ \\
\hline & -0.10 \\
\hline Homem & $(0.10)$ \\
\hline & -0.08 \\
\hline Escolaridade & $(0.06)$ \\
\hline & -0.01 \\
\hline & $(0.01)$ \\
\hline
\end{tabular}

Fonte: Pesquisa "Barômetro das Américas", 2008

$N=1386$

Erros-Padrão Robustos em Parênteses

* significativo a $10 \%$; ${ }^{* *}$ significativo a $5 \%$; ${ }^{* * *}$ significativo a $1 \%$

\section{Conclusões}

Vimos que diversos estudos creditam ao Programa Bolsa Família a reeleição de Lula (HUNTER e POWER, 2007; NICOLAU e PEIXOTO, 2007; SOARES e TERRON, 2008). Outros, embora reconheçam que o Programa foi importante, não ousam 
afirmar esta relação de forma tão contundente, relativizando a sua influência nos resultados das eleições do Poder Executivo Federal em 2006 (CARRARO et al, 2007). O fato é que, em maior ou menor medida, estudos baseados no desempenho da votação de Lula em estados e municípios indicam que o Presidente ganhou as eleições nos lugares com maior número de pobres e piores indicadores sociais, onde há proporcionalmente maior número de beneficiários do Programa Bolsa Família.

Tendo em vista que tais estudos adotaram estados ou municípios como unidade de análise, o objetivo deste artigo, a partir da base de dados da Pesquisa "Barômetro das Américas", foi verificar se este tipo de correlação também pode ser verificado no nível individual. Para isso, optamos por analisar a percepção dos beneficiários e não beneficiários do Bolsa Família quanto à avaliação do governo federal e do Presidente da República, assim como o respectivo comportamento político-eleitoral em 2008 e em 2006.

A análise dos dados permitiu identificar uma nítida diferença de opiniões e atitudes em relação ao Presidente da República e ao governo federal em ambos os grupos analisados. Os testes estatísticos realizados também permitiram reconhecer que os comportamentos de beneficiários e não beneficiários do Programa Bolsa Família são diferentes, pelo menos no que concerne às variáveis selecionadas.

Em suma, os achados deste trabalho contribuem para fortalecer a hipótese de que os beneficiários do Programa tendem a votar mais em Lula, além de avaliar o governo federal e o trabalho do Presidente de uma forma mais positiva do que os não beneficiários.

Apurar em que medida o Programa Bolsa Família contribuiu para a manutenção do Presidente Lula no poder não é apenas uma questão de identificar dividendos eleitorais de um programa federal. Passa pela análise da cultura política de uma nação tradicionalmente desigual que há muito tempo vinha oferecendo poucas possibilidades de mobilidade social. O Programa Bolsa Família representou uma nítida inflexão nesta tendência e, em que pese o fato de que ele só foi possível por conta da estabilidade econômica, de reformas estruturais anteriores e da conjuntura internacional favorável, tudo indica que os beneficiários do Programa Bolsa Família o vinculam diretamente à figura do Presidente Lula.

No que diz respeito a pensar de forma mais ampla uma teoria da escolha eleitoral, fica claro que não podem ficar ausentes de modelos explicativos visões sobre políticas sociais, corrupção, avaliação retrospectiva do estado da economia e identificação com partidos políticos, todos sendo bastante relevantes na identificação sobre como eleitores escolhem seu candidato para o cargo mais alto da hierarquia política brasileira. 


\section{Referências Bibliográficas}

CARRARO et al. It is the economy, companheiro!: uma análise empírica da reeleição de Lula com base em dados municipais. [Online]. Trabalho apresentado no $X$ Encontro de Economia da Região Sul (ANPECSUL), Porto Alegre, 2007. Disponível em:

<http://www.pucrs.br/face/ppge/anpecsul/5-07.pdf>. Acesso em 30 de julho de 2008.

CARREIRÃO, Y. A Decisão de Voto nas Eleições Presidenciais Brasileiras. Rio de Janeiro: Editora da FGV, 2002.

"Relevant Factors for the Voting Decision in the 2002 Presidential Elections: An Analysis of the ESEB (Brazilian Electoral Studies) Data". Brazilian Political Science Review, v.1, n.1, p. 70-101, 2007.

CASTRO, H. C. O. "Las políticas sociales del gobierno de Lula, son de izquierda?" Encuentro de la Cultura Cubana, v. 48/49, p. 132-136, 2008.

COHN, A. e FONSECA, A. O Bolsa Família e a questão social. [Online] Teoria e Debate. São Paulo, n. 57, mar./abr, 2004. Disponível em:

<http://www2.fpa.org.br/portal/modules/news/article.php?storyid=3184>. Acesso em: 27 jul. 2008.

HOFFMANN, R. "Transferência de renda e a redução da desigualdade no Brasil e Cinco regiões entre 1997 e 2004". Econômica. v.8, n.1, p. 55-81, Junho 2006. Disponível em: <http://www.uff.br/cpgeconomia/economica.htm>.

HUNTER, W. e POWER, T. "Rewarding Lula: Executive Power, Social Policy, and the Brazilian Elections of 2006". Latin American Politics \& Society, v.49, p. 1-30, 2007. 
IPEA. Sobre a recente queda da desigualdade de renda no Brasil. [Online]. 2006. Disponível em: <http://www.ipea.gov.br/sites/000/2/publicacoes/NTquedaatualizada.pdf>. Acesso em: 01 jul. 2008.

IPEA. Sobre a recente queda da desigualdade de renda no Brasil. [Online] 2006. Nota técnica, $\mathrm{n}$. 9, Disponível em: <http://www.ipea.gov.br>.

KING, G. A Solution to the Ecological Inference Problem: Reconstructing Individual Behavior from Aggregate Data. Princeton: Princeton University Press, 1997.

MANACORDA, M.; MIGUEL, E. e VIGORITO, A. "Government Transfers and Political Support.". NBER Working Paper Series, Working Paper 14702. Cambridge, MA, 2009.

MANHEIM, J. B. e RICHARD C. R. Empirical Political Analysis: Research Methods in Political Science. White Plains, N.Y.: Longman, 1995.

MINISTÉRIO DO DESENVOLVIMENTO SOCIAL E COMBATE À FOME. O Programa Bolsa Família, [Online]. 2008. Disponível em:

<http://www.mds.gov.br/bolsafamilia/o_programa_bolsa_familia>. Acesso em: 29 jul. 2008.

NERI, M. C. (Org.). Poverty, Inequality, and Labor Dynamics: The Second Real. Report. Rio de Janeiro: Fundação Getúlio Vargas, 2006.

NICOLAU, J. "An Analysis of the 2002 Presidential Election using Logistic Regression." Brazilian Political Science Review, v.1, n.1, p. 125-135, 2007.

NICOLAU, J. e PEIXOTO, V. Uma Disputa em Três Tempos: Uma Análise das Bases Municipais das Eleições Presidenciais de 2006. [Online]. 2007. Trabalho apresentado no XXXI Encontro Anual da ANPOCS, Caxambu. Disponível em:

<http://jaironicolau.iuperj.br/artigos/NICOLAU\%20\&\%20PEIXOTO\%20ANPOCS2007\%20ST \%2024\%20PARTIDOS\%20E\%20SISTEMAS\%20PARTIDA\%C2\%A6\%C3\%BCRIOS.pdf>.

Acesso em: 27 jul. 2008. 
PAES DE BARROS, R.; CARVALHO, M.; FRANCO, S. e MENDONÇA, R. "Uma análise das principais causas da queda recente na desigualdade de renda brasileira". Econômica. v.8, n.1. p. 55-81, Jun. 2006. Disponível em: <http://www.uff.br/cpgeconomia/economica.htm>.

RENNÓ, L. "Escândalos e voto: as eleições presidenciais brasileiras de 2006". Opinião Pública, v.13, n.2, p.260-282, 2007.

ROBINSON, W. S. "Ecological correlations and the behavior of individuals". American Sociological Review, n.15, p.351-357, 1950.

SELIGSON, M. "The Renaissance of Political Culture or the Renaissance of the Ecological Fallacy", Comparative Politics, v. 34, p. 273-292, 2002.

SOARES, F. V.; SOARES, S.; MEDEIROS, M. e OSÓRIO, R. G. Programas de Transferência de Renda no Brasil: impactos sobre a desigualdade. [Online] Ipea, 2006. (Texto para Discussão n. 1228.) Disponível em: <http://www.ipea.gov.br/default.jsp>.

SOARES, G. A. D. e TERRON, S. L. "A Geografia Eleitoral da Reeleição de Lula no Brasil: explorando conceitos, métodos e técnicas de análise geoespacial". Artigo apresentado no $\mathrm{V}$ Congresso Latino Americano de Ciência Política - ALACIP, São José da Costa Rica, 2008.

TCU. Relatório de Acompanhamento do Programa Bolsa Família. [Online]. 2007. Disponível em: http://www.projetobr.com.br/c/document_library/get_file?folderld=71\&name=DLFE. 323.pdf>. Acesso em: 30 jul. 2008. 


\section{Apêndice \\ Operacionalização das Variáveis}

Variáveis apresentadas na Tabela 4.

As questões sobre percepções sobre o governo federal foram derivadas das perguntas abaixo. As respostas se basearam em uma escala de 1 a 7 , de forma que 1 significa "nada" e 7 significa "muito".

Para a variável que mede a percepção do beneficiário do Programa Bolsa Família em relação à confiança no governo federal usamos a seguinte questão:

B14. Até que ponto o sr./sra. tem confiança no governo federal?

Em relação à confiança no Presidente da República:

B21a. Até que ponto o sr./sra. tem confiança no Presidente da República?

Em relação ao combate à pobreza:

N1. Até que ponto o sr./sra. diria que o governo federal atual combate a pobreza?

Em relação a proteção e promoção dos princípios democráticos:

N3. Até que ponto o sr./sra. diria que o governo federal atual promove e protege os princípios democráticos?

Em relação ao combate à corrupção no governo:

N9. Até que ponto o sr./sra. diria que o governo federal atual combate à corrupção no governo?

Em relação à proteção dos direitos humanos:

N10. Até que ponto o sr./sra. diria que o governo federal atual protege os direitos humanos?

Em relação à melhora na segurança do cidadão:

N11. Até que ponto o sr./sra. diria que o governo federal atual melhora a segurança do cidadão?

Em relação ao combate ao desemprego:

N12. Até que ponto o sr./sra. diria que o governo federal atual combate 0 desemprego?

Em relação à proteção do meio ambiente:

N13BRAZ. Até que ponto o sr./sra. diria que o governo federal atual investe em proteger o meio ambiente, a natureza?

A questão sobre a percepção do beneficiário do Programa Bolsa Família sobre a avaliação do trabalho do Presidente Lula baseou-se na pergunta abaixo. As respostas se basearam nas seguintes alternativas: (1) muito bom; (2) bom; (3) nem bom, nem mal (regular); (4) mal; (5) muito mal (péssimo); (8) NS/NR

M1. E falando em geral do atual governo, com o sr./sra. avalia o trabalho que o Presidente Lula está realizando?

Inserimos a palavra "negativamente" nesta variável para explicar o sinal negativo do respectivo coeficiente de correlação. 
Variáveis apresentadas nas Tabelas 5 e 6.

As questões sobre percepções sobre a economia e corrupção foram derivadas da pergunta abaixo. Os que mencionaram corrupção receberam valor 1 e os demais valor zero na variável para corrupção como problema mais grave e os que mencionaram a economia e temas relacionados receberam valor 1 , os demais valor zero para a variável economia como problema mais grave.

A4 [COA4]. Para começar, na sua opinião, qual é o problema mais grave que o país está enfrentando?

Para a variável que mede Avaliação Econômica Sociotrópica, usamos a seguinte questão:

SOCT1. Agora, falando da economia... Como o sr./sra. avalia a situação econômica do país? O sr./sra. acha que é muito boa, boa, nem boa nem má, má ou muito má?(1) Muito boa (2) Boa (3) Nem boa, nem má (regular) (4) Má (5) Muito má (péssima)

Para satisfação com a vida:

LS4. Considerando tudo que falamos desta cidade/local, o sr./sra. diria que se encontra satisfeito ou insatisfeito com o local onde vive? (1) Satisfeito insatisfeito

Para vitima de crime:

VIC1. Agora mudando de assunto, o sr./sra. foi vítima de algum ato de delinquência (assalto, roubo, sequestro relâmpago, etc..) nos últimos doze meses?

\section{(1) $\operatorname{Sim}$ [Siga] (2) Não [Vá para VIC20]}

Para atenção à mídia, somamos as respostas às perguntas abaixo. A variável resultante varia de 4 , assiste todos os dias a 16 , nunca assiste a nada.

Agora, mudando de assunto [Depois de ler cada pergunta, repetir "todos os dias", "uma ou duas vezes por semana", "raramente", ou "nunca" para ajudar o entrevistado]

\begin{tabular}{|l|c|c|c|c|}
\hline \multicolumn{1}{|c|}{ Com que frequência o sr/ sra... } & Todos os dias & $\begin{array}{c}\text { Uma ou } \\
\text { duas vezes } \\
\text { por semana }\end{array}$ & $\begin{array}{c}\text { Rarame } \\
\text { nte }\end{array}$ & Nunca \\
\hline A1. Escuta notícias na rádio & 1 & 2 & 3 & 4 \\
\hline A2. Assiste às notícias na televisão. & 1 & 2 & 3 & 4 \\
\hline A3. Lê as notícias nos jornais & 1 & 2 & 3 & 4 \\
\hline A4i. Lê ou escuta as notícias via internet & 1 & 2 & 3 & 4 \\
\hline
\end{tabular}

Para identificação com o Partido dos Trabalhadores, todos que mencionaram o PT na resposta à pergunta abaixo receberam valor 1 , os demais valor zero.

VB11. Com qual partido sr./sra. simpatiza? [Não leia a lista] 
Para posição ideológica usamos a escala com o enunciado abaixo, mas recodificamos os três valores mais à esquerda como 1 e os demais como zero para atenuar problemas de dados ausentes nessa variável. Por isso, ela é uma medida limitada de posicionamento ideológico. Como é a única disponível, optamos por mantê.la na equação.

L1. (Escala Esquerda-Direita) Nessa folha há uma escala, de 1 a 10, que vai da esquerda para a direita. Hoje em dia, quando se conversa de tendências políticas, fala-se de pessoas que simpatizam mais com a esquerda e de pessoas que simpatizam mais com a direita. De acordo com o sentido político que os termos "esquerda" e "direita" têm para o sr./sra, onde o sr./sra. se situa nesta escala? Indique o número que se aproxima mais da sua própria posição.

Para Homem, recebeu valor 1 todos os entrevistados identificados como do sexo masculino e zero para os demais.

Para Escolaridade usamos uma pergunta que estima o número de anos de escolaridade com base na seguinte pergunta:

ED. Qual foi o último ano de escola que o sr./sra. terminou Ano do (primário, secundário, universidade, superior não-universitário)

Elaine Licio - elaine.licio@gmail.com

Lucio R. Rennó - luciorenno@unb.br.

Henrique Carlos de O. de Castro - henrique@unb.br.

Recebido para publicação em outubro de 2008.

Aprovado para publicação em janeiro de 2009. 